J. Dairy Sci. 96:2847-2856

http://dx.doi.org/10.3168/jds.2012-5855

(C) American Dairy Science Association ${ }^{\circledR}$, 2013. Open access under CC BY-NC-ND license.

\title{
The effect of meloxicam on pain sensitivity, rumination time, and clinical signs in dairy cows with endotoxin-induced clinical mastitis
}

\author{
C. E. Fitzpatrick, ${ }^{11,2}$ N. Chapinal, ${ }^{*} †$ C. S. Petersson-Wolfe,‡ T. J. DeVries,§ D. F. Kelton, ${ }^{*}$ T. F. Duffield, ${ }^{*}$ \\ and K. E. Leslie* \\ *Department of Population Medicine, University of Guelph, Ontario, N1G 2W1, Canada \\ †Animal Welfare Program, University of British Columbia, Vancouver, V6T 1Z4, Canada \\ ‡Department of Dairy Science, Virginia Tech University, Blacksburg 24061 \\ §Department of Animal and Poultry Science, University of Guelph, Kemptville Campus, Ontario, K0G 1J0, Canada
}

\section{ABSTRACT}

The objectives of this study were to (1) evaluate the use of a pressure algometer and an automated rumination monitoring system to assess changes in pain sensitivity and rumination time in response to endotoxininduced clinical mastitis and (2) evaluate the effect of the nonsteroidal antiinflammatory drug meloxicam on pain sensitivity and rumination time, as well as other clinical signs, in dairy cattle with endotoxin-induced clinical mastitis. Clinical mastitis was induced in 12 primiparous and 12 multiparous lactating dairy cows by intramammary infusion of $25 \mu \mathrm{g}$ of Escherichia coli lipopolysaccharide (LPS) into 1 uninfected quarter. Immediately after, half the cows were injected subcutaneously with meloxicam (treated group) and half with the same volume of a placebo solution (control group). Pain sensitivity was assessed by measuring the difference in pressure required to elicit a response on the control and challenged quarter using an algometer $3 \mathrm{~d}$ before, immediately before, and at $3,6,12$, and $24 \mathrm{~h}$ after LPS infusion and either meloxicam or placebo injection. $\mathrm{Ru}-$ mination was continuously monitored from $2 \mathrm{~d}$ before to $3 \mathrm{~d}$ after LPS infusion using rumination loggers. Udder edema, body temperature, somatic cell score, and dry matter intake were also monitored to evaluate the occurrence and the duration of the inflammation after LPS infusion. In control animals, the difference in the pressure applied to the control and challenged quarters (control - challenged quarter) increased by $1.1 \pm 0.4$ $\mathrm{kg}$ of force $6 \mathrm{~h}$ after LPS infusion compared with the baseline, suggesting an increase in pain sensitivity in the challenged quarter. Neither the LPS infusion nor the meloxicam treatment had an effect on daily rumination time. However, the rumination diurnal pattern

Received June 20, 2012.

Accepted January 29, 2013.

${ }^{1}$ Corresponding author: colleen.e.fitzpatrick@gmail.com

${ }^{2}$ Current address: Department of Large Animal Clinical Sciences, University of Saskatchewan, Saskatoon, S7N 5B4, Canada. on the day of LPS infusion showed an overall deviation from the baseline pattern. Cows spent less time ruminating in the hours following LPS infusion and more time ruminating later in the day. Meloxicam did not alter somatic cell score or dry matter intake. However, meloxicam-treated animals had less udder edema and a lower body temperature in the hours following LPS infusion compared with control animals. In conclusion, pressure algometers and rumination loggers show promise as tools to detect mastitis and monitor recovery on farm. Further, meloxicam has a beneficial effect in relieving pain and decreasing udder edema and body temperature in LPS-induced clinical mastitis.

Key words: algometer, behavior, endotoxin challenge, nonsteroidal antiinflammatory drug

\section{INTRODUCTION}

Mastitis continues to be a prevalent and economically detrimental disease in the dairy industry. The negative effects of clinical mastitis regarding discomfort, pain, and reduced welfare are probably underestimated. In a study by Kielland et al. (2010), it was found that on a 10-point scale, dairy producers ranked only severe cases of mastitis as one of the most painful conditions in adult cattle, with a pain assessment score of 7.6 , in relation to other common health problems. Milder cases of mastitis were ranked much lower for the intensity of pain, with a pain assessment score of 5.7. However, cows can experience pain in even mild cases of mastitis and, therefore, welfare is compromised (Leslie and Petersson-Wolfe, 2012).

Measuring pain associated with mastitis is challenging. In the past, udder pain has commonly been measured with subjective scales (Banting et al., 2008). However, new technologies have been recently developed for a more objective assessment of pain. One example is the pressure algometer, which quantifies the pressure that can be exerted on a certain area of the body before the animal responds (moves away from the pressure). 
The maximum pressure applied is interpreted as the pain threshold response of the animal. The algometer has been used successfully in studies evaluating pain associated with dehorning (Heinrich et al., 2010) and lameness (Dyer et al., 2007). However, to the authors' knowledge, no previous work has used an algometer to specifically quantify udder pain associated with clinical mastitis. Recently, Bertulat et al. (2012) validated a dynamometer, which measures firmness by applying pressure in the udder. Although this tool could be useful in understanding how cows withstand pressure on their mammary quarters in cases of mastitis, it has not yet been validated for pain assessment. Other measures exist that can help assess discomfort during episodes of mastitis, such as decreased DMI, rumination time, and milk production (Fogsgaard et al., 2012). Rumination time can easily be monitored on farm by using individual rumination loggers, and shows promise as an aid in the early detection of illness (Lindgren, 2009). Siivonen et al. (2011) reported a decrease in rumination time (monitored by observation) in the hours following experimental challenge, suggesting that rumination time could be used as an indicator of systemic illness in mastitis. However, these researchers only followed 6 cows for a total of $48 \mathrm{~h}$. More research, with a larger sample of animals, continuously monitored before and after an experimental mastitis challenge is, thus, needed.

Pain management therapy with a nonsteroidal antiinflammatory drug (NSAID), such as flunixin meglumine, ketoprofen, or meloxicam, can reduce the clinical signs of mastitis (Anderson et al., 1986; Banting et al., 2008; McDougall et al., 2009). The NSAID meloxicam is approved for pain mitigation of mastitis in the European Union, China, Latin America, Australia, and New Zealand. When administered subcutaneously, it has a peak drug concentration of $4 \mathrm{~h}$ in adult cattle and a longer half-life than other commercially available NSAID (approximately $17.5 \mathrm{~h}$ ) in adult cattle (National Office of Animal Health, 2010), which is an advantage for its use on farm. Milne et al. (2003) assessed pain by applying mechanical stimuli on the hind limbs of cows with endotoxin-induced mastitis and found that cows treated with meloxicam after mastitis diagnosis returned to their normal pain thresholds faster than untreated cows. In addition, researchers have reported an improvement in milk yield, reduction in SCC, and decrease in culling risk when meloxicam has been used to treat cases of clinical mastitis (Friton and Banting, 2005; McDougall et al., 2009). Further research is needed to determine the analgesic effect of meloxicam in mastitis by assessing changes in measures of pain sensitivity, and in behavioral indicators of discomfort that can be automatically recorded on farm.
The first objective of this study was to evaluate the use of a pressure algometer and rumination loggers to assess changes in pain sensitivity and rumination time in response to endotoxin-induced clinical mastitis. To accomplish this objective, clinical signs associated with mastitis (udder edema, body temperature, SCS, and DMI) were monitored to evaluate the occurrence and duration of the clinical mastitis episode induced by the LPS infusion. The second objective was to evaluate the effect of the NSAID meloxicam on pain sensitivity, rumination time, and other clinical signs in dairy cattle with endotoxin-induced clinical mastitis.

\section{MATERIALS AND METHODS}

\section{Animals, Housing, and Management}

Twenty-four lactating dairy cows were enrolled in this study in August 2010, in groups $(\mathrm{n}=4)$ of 6 cows at a time. Only animals with no clinical signs of illness and no history of treatment for illness in the last 30 d were selected. All animals were between 10 and 100 $\mathrm{DIM}$ (mean $\pm \mathrm{SD}=57 \pm 19 \mathrm{DIM}$ ). The study group was blocked into primiparous $(\mathrm{n}=12)$ and multiparous ( $\mathrm{n}=12$, parity range $=2$ to 4$)$ groups. All animals were housed in a tiestall facility at the Ponsonby Dairy Research Centre (Ponsonby, ON, Canada). Cows were fed a TMR daily at approximately 0900, 1300, and $1500 \mathrm{~h}$, and were milked daily at approximately 0530 and $1600 \mathrm{~h}$. The experiment was approved by the University of Guelph Animal Care Committee (Guelph, ON, Canada) before the study commenced (Animal Utilization Protocol no. 10R050), and all work with animals was done according to the guidelines set by the Canadian Council on Animal Care (CCAC, 2009).

\section{Experimental Design}

Intramammary Escherichia coli LPS Infusion. Each animal was challenged in 1 quarter with an intramammary infusion of $25 \mu \mathrm{g}$ of purified bacterial Escherichia coli LPS (from E. coli 0111:B4; Sigma-Aldrich Co., St. Louis, MO) reconstituted in $10 \mathrm{~mL}$ of sterile saline solution. Only quarters with an SCC of $<200,000$ cells/mL (DeLaval direct cell counter; DeLaval International AB, Tumba, Sweden) 3 d before the challenge were eligible. Preference was given to the right hind quarter if it met the eligibility criteria. If not, the left hind quarter $(\mathrm{n}=5)$ or the right front quarter $(\mathrm{n}=$ 1) was evaluated. The infusion was performed following morning milking $(0700 \mathrm{~h})$ on the challenge day (d 0 ), after disinfecting the teat with an iodine-based teat disinfectant product. More details of the challenge procedure are described in Cyples et al. (2012). 
Experimental Treatments. Animals were randomly assigned to treatment by use of a random number generator (Random.org, Dublin, Ireland) within the parity blocks. Half the animals received meloxicam (treated group; Metacam $20 \mathrm{mg} / \mathrm{mL}$ solution; Boehringer Ingelheim $\mathrm{GmbH}$, Ingelheim am Rhein, Germany) and half received an equivalent volume of placebo solution, which was the Metacam vehicle with the active meloxicam ingredient removed (control group). The 12 control animals were the same as used by Cyples et al. (2012). Dosage was calculated based on the average weights of 10 primiparous and 10 multiparous cows from the herd. At a rate of $0.5 \mathrm{mg} / \mathrm{kg}$ (dosing volume $=2.5$ $\mathrm{mL} / 100 \mathrm{~kg}$ of $\mathrm{BW}$ ), primiparous cows received a dosage of $15 \mathrm{~mL}$, whereas multiparous cows received a dosage of $17 \mathrm{~mL}$. The injections were administered subcutaneously immediately after the E. coli LPS infusion. All researchers and technicians were blind to meloxicam/ placebo treatment throughout the process of data collection and analysis.

\section{Data Collection}

Sampling Scheme. Pain sensitivity, udder edema score, and SCC were measured at 6 different times throughout the study: $3 \mathrm{~d}$ before LPS infusion (immediately after the morning milking), immediately before the LPS infusion $(0 \mathrm{~h})$, and $3,6,12$, and $24 \mathrm{~h}$ after the LPS infusion. Rumination time and body temperature were measured continuously and DMI was collected once daily, from $2 \mathrm{~d}$ before to $3 \mathrm{~d}$ after LPS infusion.

Pain Sensitivity. Pain sensitivity was measured with a pressure algometer (Force Ten FDX 50; Wagner Instruments, Greenwich, CT), equipped with a curved pressure pad for easier application on the contour of the gland. The algometer measured the pressure in kilograms of force (kgf) that could be applied to a quarter (Figure 1). While the cow was standing square on all 4 legs, even pressure was applied with the algometer perpendicularly to the quarter, approximately $25 \mathrm{~cm}$ ventral to the udder attachments and $5 \mathrm{~cm}$ lateral to the median suspensory ligament, until the operator could not press any further or the animal had an avoidance reaction to the pressure, such as kicking or stepping away from the applied pressure. The maximum reading at the time of algometer removal indicated the level of hyperalgesia of the quarter. Pain sensitivity was measured in the challenged quarter, to measure primary hyperalgesia to the inoculation, and the ipsilateral (control) quarter, to measure secondary hyperalgesia to the inoculation. Pressure was always applied and recorded on the control quarter first, followed by the challenged quarter. The same operator took all measurements. The maximum pressure recorded throughout the experiment was $10.5 \mathrm{kgf}$. The difference between the pressure applied to the control quarter and the challenged quarter (control quarter - challenged quarter) was calculated and used as the outcome variable for the analysis of pain sensitivity.

Rumination Time. Individual rumination loggers (HR-Tag; SCR Engineers Ltd., Netanya, Israel) attached to collars were used to monitor rumination time. The rumination loggers continuously record the duration of rumination in 2-h intervals by capturing with a microphone the distinctive sounds produced when the animal regurgitates the bolus and ruminates (Schirmann et al., 2009). Data were transferred to a computer twice daily using a mobile reader (SCR Engineers Ltd.).

Edema Score. Edema was assessed on the challenged and control quarter using a 1-to- 5 scale $(1=$ no edema; $5=$ very severe edema), as described by Nestor et al. (1988).

Body Temperature. Body temperature was measured at 1-min intervals with a temperature data logger (Vemco Minilog 8; Vemco Division of AMIRIX Systems Inc., Halifax, NS, Canada). This logger was attached to a modified controlled internal drug release device (CIDR 1380; Pfizer Animal Health, Madison, NJ) and inserted vaginally into the cow, as described in Vickers et al. (2010). Data were extracted from the loggers and transferred to a computer once they were removed from the animals.

$\boldsymbol{S C S}$. Milk samples were aseptically collected to determine SCC from the challenged quarter. Samples were taken in accordance with the National Mastitis Council protocols (National Mastitis Council, Verona, WI), frozen at $-20^{\circ} \mathrm{C}$, and submitted to the Atlantic Veterinary College (Charlottetown, PEI, Canada) for analysis. Samples were then thawed, and ran through a Fossomatic cell counter (Foss Instruments, Hillerød, Denmark) for determination of SCC. The SCC values were converted to SCS using the following equation:

$$
\mathrm{SCS}=\log ^{2}(\mathrm{SCC} / 100,000)+3 .
$$

DMI. Dry matter intake for each individual cow was measured daily by subtracting the amount of TMR orts (leftover feed measured before the morning TMR delivery) from the amount of TMR delivered the previous day. On $\mathrm{d}-3,1$, and 4 relative to LPS infusion, TMR samples were collected and frozen. At a later date, these samples were thawed and dried $\left(60^{\circ} \mathrm{C}\right.$ for 48 h) to determine DM content. The $3 \mathrm{DM}$ content values estimated per enrollment group were averaged and used to calculate DMI. 


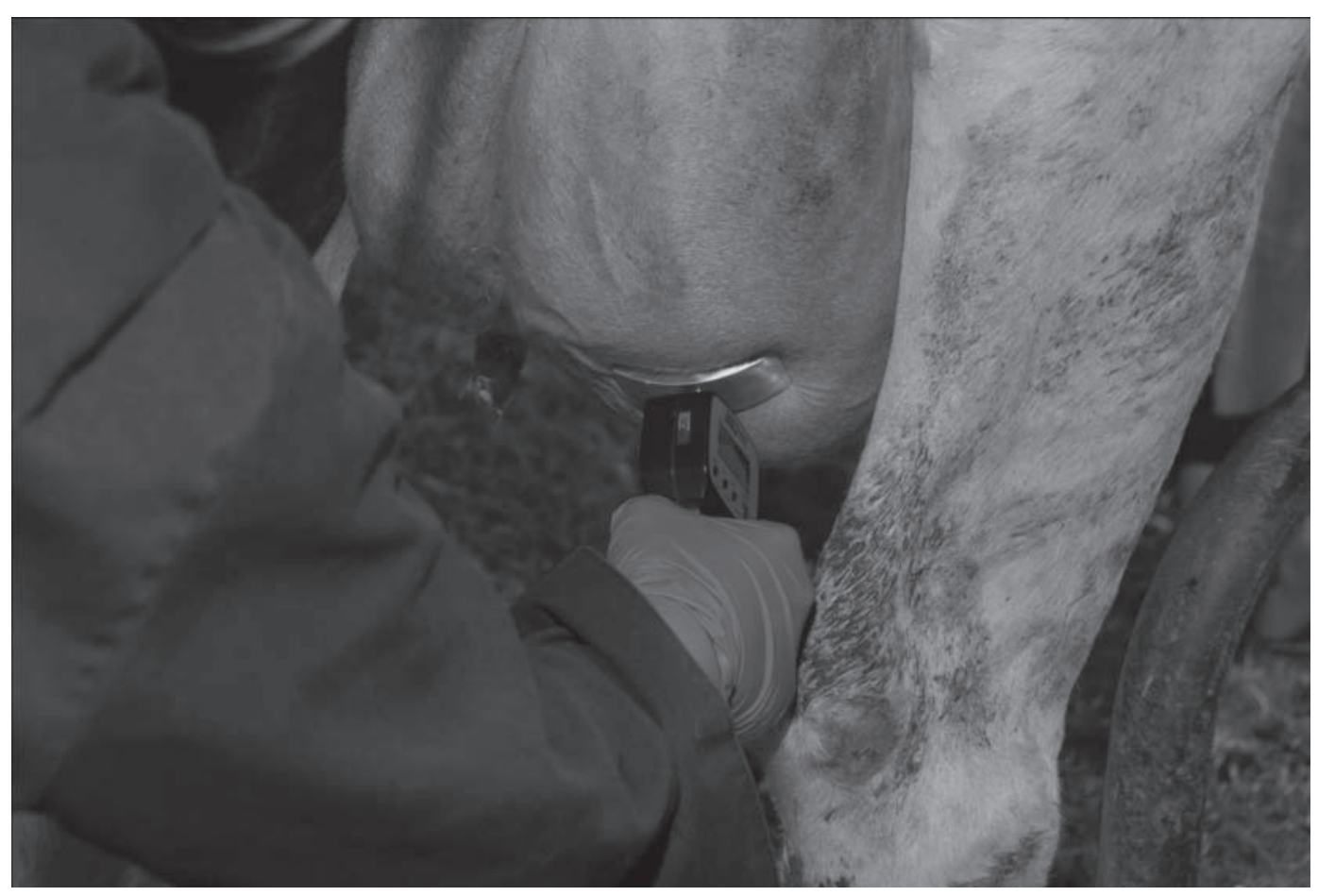

Figure 1. Pain sensitivity measured with a Force Ten FDX 50 pressure algometer (Wagner Instruments, Greenwich, CT), equipped with a curved pressure pad, applied perpendicularly to the quarter, approximately $25 \mathrm{~cm}$ ventral to the udder attachments and $5 \mathrm{~cm}$ lateral to the median suspensory ligament.

\section{Data Analysis}

All statistical analyses were performed with SAS (version 9.2; SAS Institute Inc., Cary, NC), considering cow as the experimental unit. Experimental days were adjusted to start at $0800 \mathrm{~h}$, as this was the time by which all cows were infused with LPS. Rumination data were summarized to obtain 1 value per cow and day. An exploratory analysis showed no differences in the measures of pain sensitivity and SCS on d -3 and $\mathrm{h} 0$ relative to LPS infusion, and the measures of rumination time and DMI collected on $\mathrm{d}-2$ and $\mathrm{d}-1$ relative to LPS infusion. Therefore, these measurements were averaged to obtain 1 baseline value per cow. Edema scores of the challenged quarter were 1 (no edema) before LPS infusion in all cases and, therefore, the baseline was not included in the analysis. Data were analyzed using mixed models (PROC GLIMMIX) that included time as a repeated measure over cow, parity (primiparous or multiparous), and treatment as fixed effects, and the biologically plausible 2-way interactions. The covariance structure was selected based on the smallest Akaike information criterion. Variables and interactions were removed from the final model if $P>0.05$ by manual backward elimination. Dunnett's 2 -tailed test was used as a post hoc test to evaluate differences between baseline and subsequent time periods.
If the treatment $\times$ time interaction was significant at $P \leq 0.05$, differences between baseline and subsequent time periods were evaluated within treatment. Residuals were examined to verify normality and homogeneity of variances, and to detect possible outliers and influential points.

Rumination data were summarized by cow, day, and 2-h intervals to assess diurnal patterns. Similarly, body temperature data were summarized by cow, day, and hour. An exploratory analysis showed that diurnal patterns on d 2 and 1 were very similar and, therefore, data were averaged to create a baseline diurnal pattern for each variable. Deviations from baseline in the diurnal pattern were limited to d 0 and, therefore, the analysis focused on these 2 time periods. In the case of rumination, data were analyzed using a similar mixed model to the one described above, but including time period (baseline or d 0) and 2-h intervals within period as repeated measures over cow. In the case of body temperature, the exploratory analysis revealed an interaction between treatment, time, and hour. Therefore, the analysis was stratified by time and the models included hour as a repeated measure over cow, parity, and treatment as fixed effects, and the biologically plausible 2 -way interactions. Residuals were examined to verify normality and homogeneity of variances, and to detect possible outliers and influential points. 


\section{RESULTS}

\section{Pain Sensitivity}

When the difference of pressure applied to the control and challenged quarter was analyzed as a measure of pain sensitivity, an interaction was observed between treatment and time $(P=0.02$; Figure 2$)$. Therefore, the baseline period was compared with the subsequent time periods within each treatment. Whereas no differences over time were found in the meloxicam-treated cows, the difference in pressure applied to the control and challenged quarters of control cows increased at $6 \mathrm{~h}$ $(1.1 \pm 0.4$ kgf; $P=0.04)$ after LPS infusion compared with the baseline. No effect of parity on pain sensitivity was observed $(P=0.53)$.

\section{Rumination Time}

Due to technical problems, rumination data from 2 cows, 1 of each treatment group, were not available. Daily rumination time was not affected by LPS infusion $(P=0.74$ for the effect of time relative to LPS infusion) or by treatment $(P=0.74)$, and the interaction between treatment and time was not significant $(P=0.84)$. Overall, multiparous cows spent more time ruminating than primiparous cows (553 vs. $413 \mathrm{~min} / \mathrm{d}$; standard error of the difference $=43 ; P=0.004)$. However, when diurnal patterns were assessed (Figure 3), an interaction between time (expressed as baseline or $\mathrm{d}$ $0)$ and 2 -h interval $(P<0.001)$ was observed after con- trolling for parity. The diurnal pattern on d 0 showed a deviation from the baseline diurnal pattern such that cows spent less time ruminating following LPS infusion and more time ruminating later in the day.

\section{Clinical Signs}

Edema Score. At the time of enrollment, none of the cows presented edema in the quarter selected to be challenged, whereas 1 cow presented slight edema in the control quarter (score $=2$ ). No major changes occurred in the control quarter throughout the study. However, the LPS infusion caused some degree of udder edema (score $\geq 2$ ) in the challenged quarter of all animals. Edema scores peaked $6 \mathrm{~h}$ after LPS infusion (Table 1). Overall, control cows had higher edema scores than meloxicam-treated cows after LPS infusion.

Body Temperature. Two temperature loggers, 1 of each treatment group, were lost during the study and, therefore, data from these 2 cows were not available. When the diurnal patterns of body temperature were assessed, a treatment by hour interaction was observed on d $0(P=0.03$; Figure 4$)$. In the hours following LPS infusion, body temperature increased faster in control animals, reaching a higher peak temperature than meloxicam-treated animals.

$\boldsymbol{S C S}$. No treatment effect or treatment by time interaction was observed on SCS (Table 1). However, an overall time effect was observed, such that SCS increased at $6(2.1 \pm 0.5 ; P<0.001), 12(3.7 \pm 0.6 ; P$

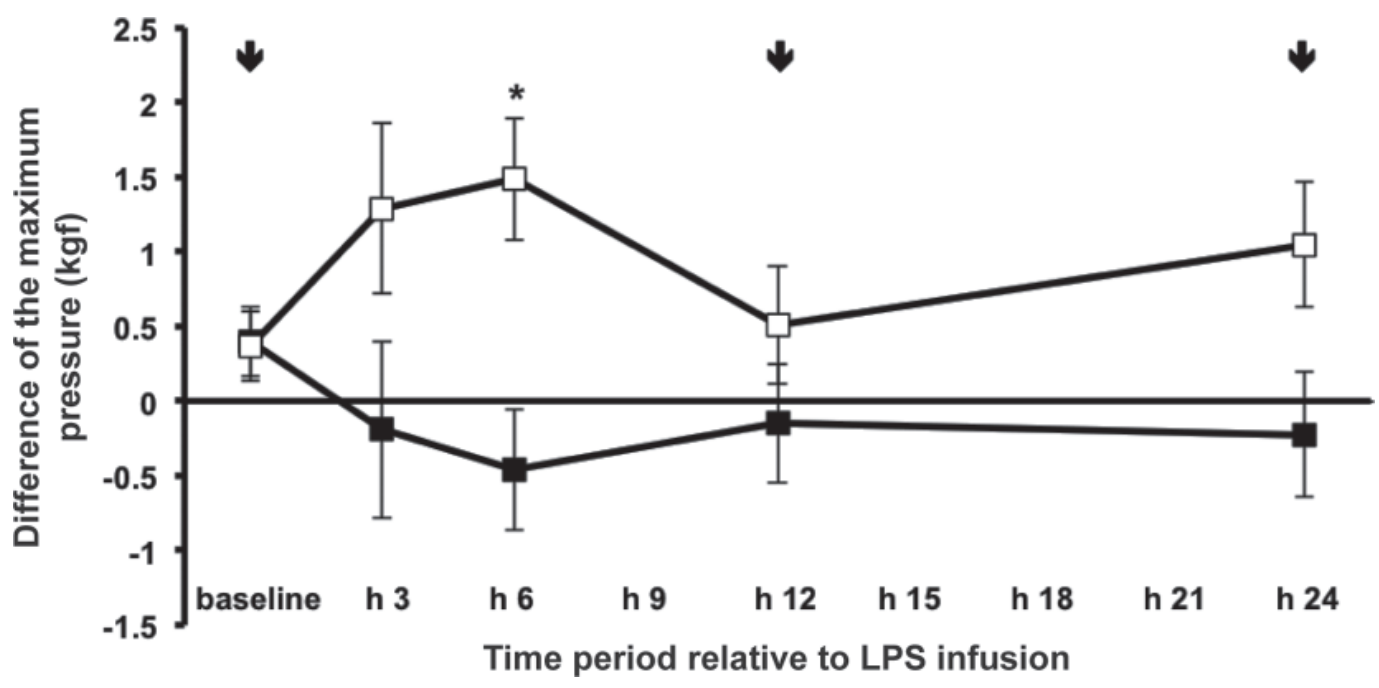

Figure 2. Least squares means $( \pm \mathrm{SEM})$ difference of the maximum pressure (kilograms of force; kgf) applied to the control and the challenged quarter (control quarter - challenged quarter) of 24 Holstein dairy cows before (baseline) and after (h 3, 6, 12, and 24) intramammary infusion with Escherichia coli LPS and injection with either meloxicam $(\mathrm{n}=12 ; \mathbf{\square})$ or placebo solution $(\mathrm{n}=12 ; \square)$. The baseline was calculated by averaging the maximum pressure recorded $3 \mathrm{~d}$ before and immediately before the LPS infusion. Cows were milked at approximately 0530 and $1600 \mathrm{~h}$ (downward arrows), and samples scheduled at this time were taken following milking. ${ }^{*} P \leq 0.05$ when baseline was compared with subsequent time periods within each treatment (Dunnett's 2-tailed test). 
Table 1. Least squares means $( \pm$ SEM) edema scores and SCS of the challenged quarter of 24 Holstein dairy cows before (baseline) and after (h 3,6,12, and 24) intramammary infusion with Escherichia coli LPS and injection with either meloxicam or placebo solution

\begin{tabular}{|c|c|c|c|c|}
\hline \multirow[b]{2}{*}{ Item } & \multicolumn{2}{|c|}{ Edema score } & \multicolumn{2}{|c|}{ SCS } \\
\hline & Control & Meloxicam & Control & Meloxicam \\
\hline \multicolumn{5}{|l|}{ Time } \\
\hline Baseline & 1 & 1 & $2.4 \pm 0.6$ & $2.3 \pm 0.6$ \\
\hline $3 \mathrm{~h}$ & $2.8 \pm 0.2$ & $2.3 \pm 0.2$ & $2.8 \pm 0.6$ & $2.4 \pm 0.6$ \\
\hline $6 \mathrm{~h}$ & $3.5 \pm 0.2$ & $2.8 \pm 0.2$ & $4.9 \pm 0.6$ & $4.0 \pm 0.6$ \\
\hline $12 \mathrm{~h}$ & $2.9 \pm 0.2$ & $2.6 \pm 0.2$ & $7.2 \pm 0.7$ & $5.0 \pm 0.7$ \\
\hline $24 \mathrm{~h}$ & $2.0 \pm 0.2$ & $1.4 \pm 0.2$ & $9.0 \pm 0.3$ & $8.7 \pm 0.3$ \\
\hline$P$-value parity & \multicolumn{2}{|c|}{0.06} & \multicolumn{2}{|c|}{0.54} \\
\hline$P$-value treatment & \multicolumn{2}{|c|}{0.01} & \multicolumn{2}{|c|}{0.25} \\
\hline$P$-value time & \multicolumn{2}{|c|}{$<0.001$} & \multicolumn{2}{|c|}{$<0.001$} \\
\hline$P$-value treatment $\times$ time & \multicolumn{2}{|c|}{0.56} & \multicolumn{2}{|c|}{0.29} \\
\hline
\end{tabular}

$<0.001)$, and $24 \mathrm{~h}(6.5 \pm 0.3 ; P<0.001)$ after LPS infusion compared with the baseline values.

$\boldsymbol{D} \boldsymbol{M I}$. One cow was removed from DMI analysis as she was identified as an extreme outlier, with excessively low DMI throughout the study period. This cow was diagnosed with a displaced abomasum a few days later, which may explain her sudden decrease in DMI. Overall, multiparous cows had a higher DMI than primiparous cows $(22.1 \mathrm{~kg}$ vs. $18.5 \mathrm{~kg}$; standard error of the difference $=0.8 ; P<0.001)$. No effect was observed of treatment $(P=0.62)$ or treatment by time interaction $(P=0.33)$ on DMI. However, an overall decrease in DMI of $1.0 \pm 0.3 \mathrm{~kg}(P=0.004)$ on d 0 compared with baseline was observed.

\section{DISCUSSION}

\section{Effects of Endotoxin-Induced Clinical Mastitis on Pain Sensitivity and Rumination Time}

The LPS infusion resulted in a consistent, moderateto-severe case of clinical mastitis of limited duration (less than $24 \mathrm{~h}$ ) in all cows. In the hours following LPS infusion, an overall increase was observed in edema score, SCS, and body temperature. Clinical signs (edema scores and body temperature) were the most severe $6 \mathrm{~h}$ after LPS infusion, which is in agreement with previous studies that measured local signs of inflammation in the udder and rectal temperature after similar endotoxin challenges (Banting et al., 2000; Siivonen et

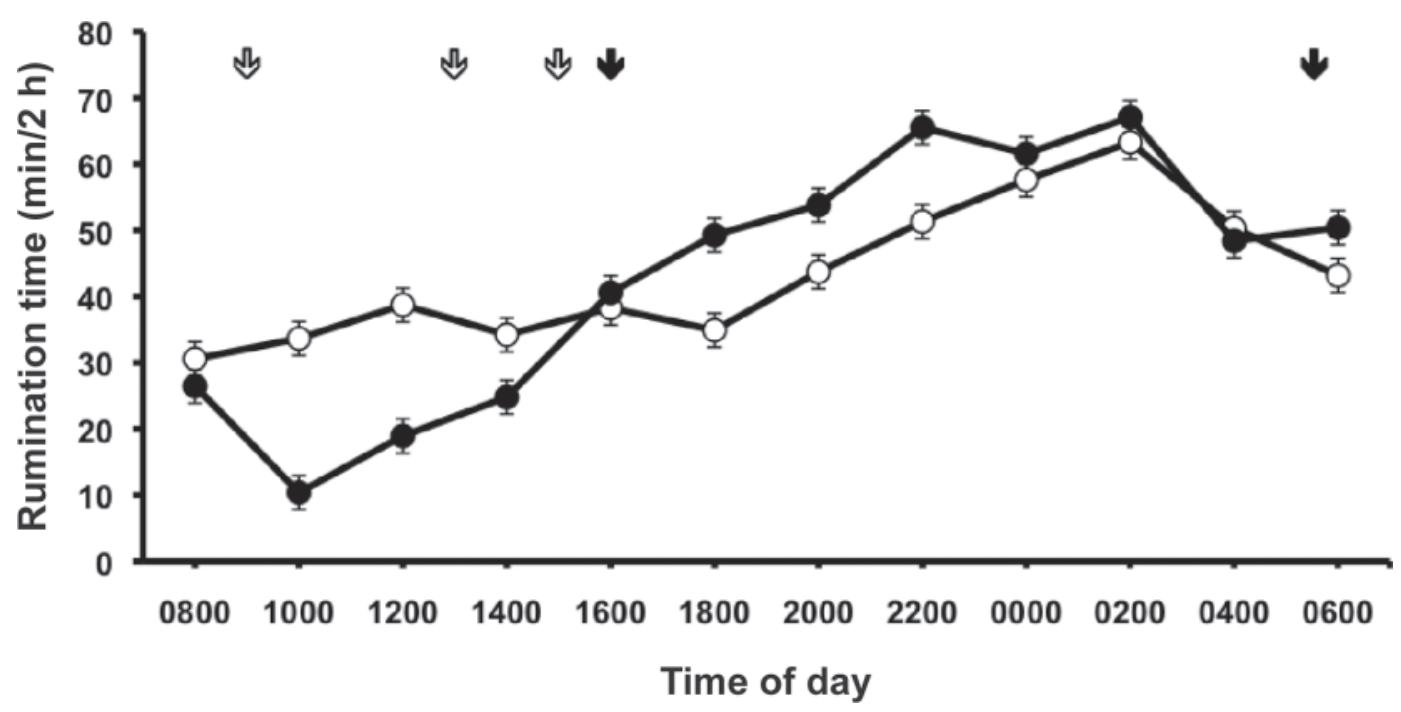

Figure 3. Least squares means $( \pm \mathrm{SEM})$ rumination time $(\mathrm{min} / 2 \mathrm{~h})$ of 22 Holstein dairy cows before (baseline; $\bigcirc)$ and on the day $(\bullet)$ of intramammary infusion with Escherichia coli LPS. Experimental days were adjusted to start at 0800 h, by which time all cows had received the LPS infusion. Cows were fed at approximately 0900, 1300, and $1500 \mathrm{~h}$ (open downward arrows) and milked at approximately 0530 and $1600 \mathrm{~h}$ (solid downward arrows). 


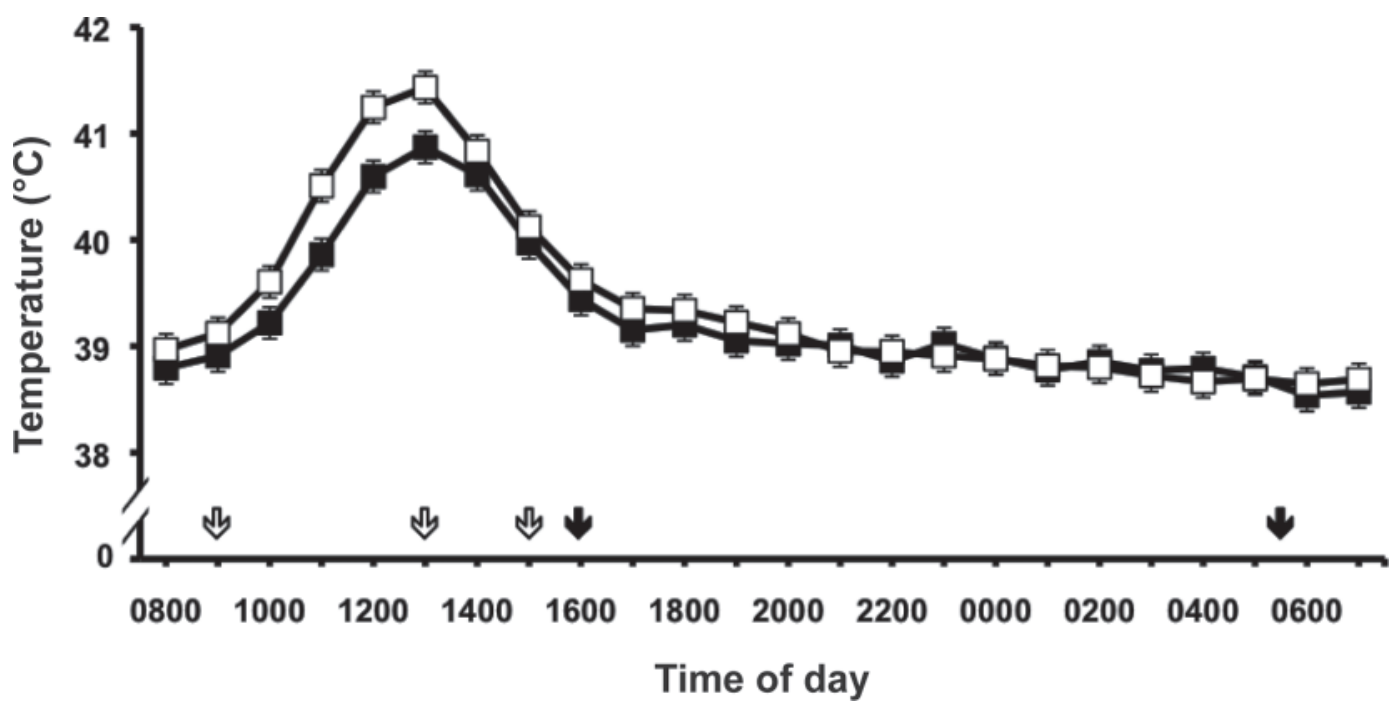

Figure 4. Least squares means $( \pm \mathrm{SEM})$ body temperature $\left({ }^{\circ} \mathrm{C}\right)$ of 24 Holstein dairy cows on the day of (d 0$)$ intramammary infusion with Escherichia coli LPS and injection with either meloxicam $(\mathrm{n}=12 ; \boldsymbol{\square})$ or placebo solution $(\mathrm{n}=12$; $\square)$. The experimental day was adjusted to start at $0800 \mathrm{~h}$, by which time all cows had received the LPS infusion. Cows were fed at approximately 0900, 1300, and 1500 h (open downward arrows) and milked at approximately 0530 and $1600 \mathrm{~h}$ (solid downward arrows).

al., 2011; Zimov et al., 2011). Similar to those studies, SCS in the current study showed a consistent increase starting at $6 \mathrm{~h}$ after LPS infusion, such that SCS were still higher than baseline at $24 \mathrm{~h}$ after LPS infusion.

To the knowledge of the authors, this is the first study to evaluate the use of a pressure algometer to assess changes in pain sensitivity of the udder in response to endotoxin-induced clinical mastitis. However, algometers have been successfully used to assess pain in lameness (Dyer et al., 2007; Liu et al., 2009; Wu et al., 2011) and dehorning (Heinrich et al., 2010) in dairy cattle. This study showed an increase in the difference of pressure applied to the control and challenged quarter in control animals $6 \mathrm{~h}$ after the LPS infusion, suggesting an increase in pain sensitivity in the challenged quarter. Banting et al. (2008) also detected an increase in pain sensitivity at udder palpation in the hours following experimental induction of mastitis. These results suggest that the algometer can detect pain at the time when the most severe signs of endotoxin mastitis occur.

Cows experienced a decrease in rumination time in the hours following the LPS infusion. Siivonen et al. (2011) also found a decrease in rumination, assessed by visual observation between 4 and $8 \mathrm{~h}$ after LPS infusion, compared with the previous day. A decrease in rumination has been reported to be indicative of stress (Anderson and Muir, 2005; Bristow and Holmes, 2007), disease (Collier et al., 1982), and pain (Anderson and Muir, 2005). Similarly to cows in the study of Siivonen et al. (2011), cows in the current study compensated for the decrease in rumination later in the day, such that no differences existed in total daily rumination time before and after LPS infusion. On the other hand, cows experienced a mild decrease in daily DMI on the day of the challenge. Zimov et al. (2011) did not find any effect of the LPS infusion on DMI, whereas Yeiser et al. (2012) found a decrease in DMI $2 \mathrm{~d}$ after infusing E. coli in the mammary gland. The association between DMI and rumination is also unclear. Schirmann et al. (2012) found a negative correlation between daily DMI and rumination time, although a positive correlation between hourly DMI and the rumination occurred $4 \mathrm{~h}$ later. Unfortunately, we could not monitor DMI continuously to assess when the decrease in DMI happened. However, as the decrease in rumination time happened $2 \mathrm{~h}$ after the LPS infusion, we suggest that at least part of the decrease in rumination cannot be attributed merely to a decrease in DMI. Further research is needed to clarify the mechanism by which LPS caused a decrease in rumination.

\section{Effects of Meloxicam on Pain Sensitivity, Rumination Time, and Clinical Signs in Endotoxin-Induced Clinical Mastitis}

Udder pain sensitivity, as measured by a pressure algometer, increased after mastitis induction in control animals but not in meloxicam-treated animals. Similarly, Heinrich et al. (2010) found that, following dehorning, double the amount of pressure could be applied to the area of dehorning in calves that received meloxicam compared with the calves that received a placebo so- 
lution. In other studies, the effect of meloxicam after experimental induction of mastitis was evaluated using different methods to score pain. Banting et al. (2000) found a more rapid decrease in pain sensitivity score (assessed by local palpation of the udder) following endotoxin infusion in the animals that received meloxicam intravenously $4 \mathrm{~h}$ after the endotoxin infusion compared with the control animals. In addition, Milne et al. (2003) found, when assessing pain applying mechanical stimuli to the hind limbs, that animals treated with meloxicam intravenously on the day of endotoxin challenge (at the time of diagnosis) returned to their normal pain threshold faster than their untreated counterparts. These findings suggest that meloxicam can alleviate the udder pain experienced after endotoxin infusion. Meloxicam may attenuate udder hyperalgesia because of several changes associated with inhibition of cyclooxygenase (COX)-2: reduced localized inflammatory mediators, reduced sensitization of peripheral afferent nociceptors, and central effects at the level of the spinal cord (Vane et al., 1998). Other studies have found similar results using other NSAID. Banting et al. (2008) found that animals treated with ketoprofen, either orally or intramuscularly $2 \mathrm{~h}$ after the endotoxin infusion, experienced a peak in pain sensitivity at udder palpation $4 \mathrm{~h}$ after the endotoxin infusion, and this peak decreased rapidly. Control animals had a peak in pain sensitivity at $6 \mathrm{~h}$ after the endotoxin infusion, which decreased more gradually than in the case of ketoprofen-treated animals. Similarly, Lohuis et al. (1991) found that animals treated with carprofen intravenously $2 \mathrm{~h}$ after the endotoxin infusion had decreased swelling and pain at udder palpation, approximately 5 to $13 \mathrm{~h}$ after carprofen injection, compared with their control counterparts.

Meloxicam did not affect daily rumination time, as measured by rumination collars. This result is in disagreement with Banting et al. (2000), who reported an increase in rumen contractions (assessed by visual observation) when administering meloxicam intravenously $4 \mathrm{~h}$ after endotoxin infusion. Other studies also found a short-term beneficial effect of other NSAID on rumination after experimentally inducing mastitis, including flunixin meglumine (Lohuis et al., 1989; Wagner and Apley, 2004), flurbiprofen (Lohuis et al., 1989), carprofen (Vangroenweghe et al., 2005), and ketoprofen (Banting et al., 2008). This discrepancy with previous studies was unexpected, as the method of monitoring rumen activity in the current study is more objective and continuous than the subjective methods used in most of the previous studies. Nevertheless, Zimov et al. (2011) did not find a significant improvement in rumination when flunixin meglumine was administered intravenously $4 \mathrm{~h}$ after endotoxin infusion. Further re- search is needed with naturally occurring cases of $E$. coli mastitis, where signs of mastitis are likely present for longer and the effect of meloxicam could be more easily assessed. The rumination loggers used in the current study can monitor rumination continuously for longer periods of time in a large number of cows and, therefore, are a promising tool to use in large-scale studies on farm.

Overall, meloxicam-treated cows had a lower edema score (i.e., less local inflammation) than control cows in the $24 \mathrm{~h}$ following LPS infusion and treatment. This is in agreement with Friton et al. (2002), who found a decrease in edema $2 \mathrm{~d}$ after endotoxin infusion in animals treated intravenously with meloxicam compared with control animals. Similar effects have been found when administering other NSAID after experimental induction of mastitis, such as carprofen (Lohuis et al., 1991) and flunixin meglumine (Anderson et al., 1986).

The body temperature of control animals increased more rapidly and peaked higher than that of meloxicamtreated animals. This result contradicts Banting et al. (2000), who measured rectal temperature at 2-h intervals and did not find any beneficial effect of meloxicam. Differences between studies could be partly due to differences in the temperature-recording methods (vaginal vs. rectal sampling and 1-min vs. 2-h intervals). Nevertheless, the antipyretic properties of meloxicam are not well understood. Whereas other NSAID are known for their antipyretic properties, such as the COX-1 preferentially inhibiting the drugs ketoprofen and carprofen, meloxicam preferentially inhibits COX-2 enzymes at the inflammation site; therefore, its COX-1 activity is limited (Lees et al., 2004). Future research is needed to explore the beneficial short-term effects of meloxicam on body temperature in clinical episodes of mastitis.

The SCS did not decrease after treatment with meloxicam, in agreement with other studies that treated cows intravenously with flunixin meglumine (Anderson and Hunt, 1989; Zimov et al., 2011) and carprofen (Vangroenweghe et al., 2005) after endotoxin infusion. Similarly, Yeiser et al. (2012) did not find an effect of flunixin meglumine on SCC, even though mastitis was induced by infusing $E$. coli rather than the endotoxin. However, McDougall et al. (2009) reported a decrease in SCS when treating naturally occurring mastitis with meloxicam, suggesting that some of the effects of NSAID might be difficult to assess in experimentally induced mastitis.

Meloxicam did not reverse the decrease in DMI observed after inducing mastitis. This lack of effect of meloxicam is in agreement with Zimov et al. (2011), who treated cows with flunixin meglumine after experimentally inducing mastitis with LPS. In contrast, Yeiser et al. (2012) found that flunixin meglumine injected 
intravenously after E. coli infusion counteracted the decrease in DMI that nontreated animals experienced 1 $\mathrm{d}$ after the infusion. However, this effect was limited in time, as treated animals showed a decrease in DMI $2 \mathrm{~d}$ after the challenge.

\section{CONCLUSIONS}

Udder pain sensitivity, as measured by a pressure algometer, increased after mastitis induction in control animals but not in meloxicam-treated animals. Overall, rumination time was reduced in the hours following infusion. Thus, pressure algometers and rumination loggers show promise as tools to monitor mastitis. Meloxicam had a beneficial effect in relieving udder pain in the hours following LPS infusion and reducing udder edema and body temperature, although it did not alter rumination time, DMI, or SCS.

\section{ACKNOWLEDGMENTS}

The authors thank Paisley Canning for her assistance with data collection, as well as Jeff McFarlane, Laura Wright (all from the University of Guelph, Guelph, ON, Canada)and the staff of the University of Guelph Ponsonby Dairy Research Centre for technical assistance throughout this study. The study was generously funded by Boehringer Ingelheim (Canada) Ltd. (Burlington, ON, Canada), as well as National Sciences and Engineering Research Council of Canada (NSERC, Ottawa, ON, Canada); Alberta Milk (Edmonton, AB, Canada); Dairy Farmers of New Brunswick (Sussex, Canada), Nova Scotia (Lower Truro, Canada), Ontario (Mississauga, Canada), and Prince Edward Island (Charlottetown, Canada); Novalait Inc. (Québec, QC, Canada); Dairy Farmers of Canada (Ottawa, ON, Canada); Canadian Dairy Network (Guelph, ON, Canada); Agriculture and Agri-Foods Canada (Ottawa, ON, Canada); Public Health Agency of Canada (Ottawa, ON, Canada); Technology PEI Inc. (Charlottetown, PE, Canada); Université de Montréal (Montréal, QC, Canada), and the University of Prince Edward Island (Charlottetown, PE, Canada), through a grant from the Canadian Bovine Mastitis Research Network. N. Chapinal was supported by a Beatriu de Pinós postdoctoral grant from the Generalitat de Catalunya (Barcelona, Spain).

\section{REFERENCES}

Anderson, D. E., and W. W. Muir. 2005. Pain management in cattle. Vet. Clin. North Am. Food Anim. Pract. 21:623-635.

Anderson, K. L., and E. Hunt. 1989. Anti-inflammatory therapy in acute endotoxin-induced bovine mastitis. Vet. Res. Commun. 13:17-26.
Anderson, K. L., A. R. Smith, R. D. Shanks, L. E. Davis, and B. K. Gustafsson. 1986. Efficacy of flunixin meglumine for the treatment of endotoxin-induced bovine mastitis. Am. J. Vet. Res. 47:13661372 .

Banting, A., S. Banting, K. Heinonen, and K. Mustonen. 2008. Efficacy of oral and parenteral ketoprofen in lactating cows with endotoxin-induced acute mastitis. Vet. Rec. 163:506-509.

Banting, A., H. Schmidt, and S. Banting. 2000. Efficacy of meloxicam in lactating cows with E. coli endotoxin-induced acute mastitis. J. Vet. Pharmacol. Ther. 23(Suppl. 1):E4. (Abstr.)

Bertulat, S., C. Fischer-Tenhagen, A. Werner, and W. Heuwieser. 2012. Technical note: Validating a dynamometer for noninvasive measuring of udder firmness in dairy cows. J. Dairy Sci. 95:6550-6556.

Bristow, D. J., and D. S. Holmes. 2007. Cortisol levels and anxietyrelated behaviors in cattle. Physiol. Behav. 90:626-628.

CCAC (Canadian Council on Animal Care). 2009. CCAC Guidelines On: The Care and Use of Farm Animals in Research, Teaching and Testing. CCAC, Ottawa, Canada.

Collier, R. J., D. K. Beede, W. W. Thatcher, L. A. Israel, and C. J. Wilcox. 1982. Influences of environment and its modification on dairy animal health and production. J. Dairy Sci. 65:2213-2227.

Cyples, J. A., C. E. Fitzpatrick, K. E. Leslie, T. J. DeVries, D. B. Haley, and N. Chapinal. 2012. Short communication: The effects of experimentally induced Escherichia coli clinical mastitis on lying behavior of dairy cows. J. Dairy Sci. 95:2571-2575.

Dyer, R. M., N. K. Neerchal, U. Tasch, Y. Wu, P. Dyer, and P. G. Rajkondawar. 2007. Objective determination of claw pain and its relationship to limb locomotion score in dairy cattle. J. Dairy Sci. 90:4592-4602.

Fogsgaard, K. K., C. M. Røntved, P. Sørensen, and M. S. Herskin. 2012. Sickness behavior in dairy cows during Escherichia coli mastitis. J. Dairy Sci. 95:630-638.

Friton, G. M., and A. Banting. 2005. Evaluation of the economic benefit of systemic treatment with the NSAID meloxicam (Metacam) in endotoxin-induced bovine clinical mastitis. Page 252 in Mastitis in Dairy Production. H. Hogeveen, ed. Wageningen Academic Publishers, Wageningen, the Netherlands.

Friton, G. M., H. Philipp, and R. Kleemann. 2002. Clinical efficacy of meloxicam (Metacam) in lactating cows with acute mastitis. Page 427 in Proc. World Buiatr. Congr., Hannover, Germany. World Association of Buiatrics, German Association for Buiatrics, Hanover, Germany.

Heinrich, A., T. F. Duffield, K. D. Lissemore, and S. T. Millman. 2010. The effect of meloxicam on behavior and pain sensitivity of dairy calves following cautery dehorning with a local anesthetic. J. Dairy Sci. 93:2450-2457.

Kielland, C., E. Skjerve, O. Østerås, and A. J. Zanella. 2010. Dairy farmer attitudes and empathy toward animals are associated with animal welfare indicators. J. Dairy Sci. 93:2998-3006.

Lees, P., M. F. Landoni, J. Giraudel, and P.-L. Toutain. 2004. Pharmacodynamics and pharmacokinetics of nonsteroidal anti-inflammatory drugs in species of veterinary interest. J. Vet. Pharmacol. Ther. 27:479-490.

Leslie, K. E., and C. S. Petersson-Wolfe. 2012. Assessment and management of pain in dairy cows with clinical mastitis. Vet. Clin. North Am. Food Anim. Pract. 28:289-305.

Lindgren, E. 2009. Validation of rumination measurement equipment and the role of rumination in dairy cow time budgets. MS Thesis. Swedish University of Agricultural Sciences, Uppsala, Sweden.

Liu, J., N. K. Neerchal, U. Tasch, R. M. Dyer, and P. G. Rajkondawar. 2009. Enhancing the prediction accuracy of bovine lameness models through transformations of limb movement variables. J. Dairy Sci. 92:2539-2550.

Lohuis, J. A. C. M., W. Van Leeuwen, J. H. M. Verheijden, A. Brand, and A. S. J. P. A. M. Van Miert. 1989. Flunixin meglumine and flurbiprofen in cows with experimental Escherichia coli mastitis. Vet. Rec. 124:305-308.

Lohuis, J. A. C. M., T. Van Werven, A. Brand, A. S. J. P. A. M. Van Miert, E. Rohde, B. Ludwig, P. Heizmann, and W. F. Rehm. 1991. Pharmacodynamics and pharmacokinetics of carprofen, a non-steroidal anti-inflammatory drug, in healthy cows and cows 
with Escherichia coli endotoxin-induced mastitis. J. Vet. Pharmacol. Ther. 14:219-229.

McDougall, S., M. A. Bryan, and R. M. Tiddy. 2009. Effect of treatment with the nonsteroidal antiinflammatory meloxicam on milk production, somatic cell count, probability of re-treatment, and culling of dairy cows with mild clinical mastitis. J. Dairy Sci. 92:4421-4431.

Milne, M. H., A. M. Nolan, P. J. Cripps, and J. L. Fitzpatrick. 2003. Assessment and alleviation of pain in dairy cattle with clinical mastitis. Cattle Pract. 11:289-293.

National Office of Animal Health. 2010. Metacam $20 \mathrm{mg} / \mathrm{ml}$ solution for injection for cattle, pigs and horses: Further information. Accessed July 16, 2012. http://www.noahcompendium.co.uk/ Boehringer_Ingelheim_Limited/Metacam_20_mg_ml_Solution_ for_Injection_for_Cattle_Pigs_and_Horses/-26598.html.

Nestor, K. E., R. W. Hemken, and R. J. Harmon. 1988. Influence of sodium chloride and potassium bicarbonate on udder edema and selected blood parameters. J. Dairy Sci. 71:366-372.

Schirmann, K., N. Chapinal, D. M. Weary, W. Heuwieser, and M. A. G. von Keyserlingk. 2012. Rumination and its relationship to feeding and lying behavior in Holstein dairy cows. J. Dairy Sci. 95:3212-3217.

Schirmann, K., M. A. G. von Keyserlingk, D. M. Weary, D. M. Veira, and W. Heuwieser. 2009. Technical note: Validation of a system for monitoring rumination in dairy cows. J. Dairy Sci. 92:6052-6055.

Siivonen, J., S. Taponen, M. Hovinen, M. Pastell, B. J. Lensink, S. Pyörälä, and L. Hänninen. 2011. Impact of acute clinical mastitis on cow behaviour. Appl. Anim. Behav. Sci. 132:101-106.
Vane, J. R., Y. S. Bakhle, and R. M. Botting. 1998. Cyclooxygenases 1 and 2. Annu. Rev. Pharmacol. Toxicol. 38:97-120.

Vangroenweghe, F., L. Duchateau, P. Boutet, P. Lekeux, P. Rainard, M. J. Paape, and C. Burvenich. 2005. Effect of carprofen treatment following experimentally induced Escherichia coli mastitis in primiparous cows. J. Dairy Sci. 88:2361-2376.

Vickers, L. A., O. Burfeind, M. A. G. von Keyserlingk, D. M. Veira, D. M. Weary, and W. Heuwieser. 2010. Technical note: Comparison of rectal and vaginal temperatures in lactating dairy cows. J. Dairy Sci. 93:5246-5251.

Wagner, S. A., and M. D. Apley. 2004. Effects of two anti-inflammatory drugs on physiologic variables and milk production in cows with endotoxin-induced mastitis. Am. J. Vet. Res. 65:64-68.

Wu, Y., N. Neerchal, R. Dyer, U. Tasch, and P. G. Rajkondawar. 2011. Modeling bovine lameness with limb movement variables. J. Biomed. Sci. Eng. 4:419-425.

Yeiser, E. E., K. E. Leslie, M. L. McGilliard, and C. S. Petersson-Wolfe. 2012. The effects of experimentally induced Escherichia coli mastitis and flunixin meglumine administration on activity measures, feed intake, and milk parameters. J. Dairy Sci. 95:4939-4949.

Zimov, J. L., N. A. Botheras, W. P. Weiss, and J. S. Hogan. 2011. Associations among behavioral and acute physiologic responses to lipopolysaccharide-induced clinical mastitis in lactating dairy cows. Am. J. Vet. Res. 72:620-627. 